\title{
El fideicomiso de acciones de la sociedad con- cesionaria como garantía de los acreedores en la concesión de obra con servicio público en Costa Rica
}

\section{The trust shares of the concessionaire company as security for creditors in concession of public works and public servi- ces in Costa Rica}

LUIS A. ORTIZ ZAMORA*

Resumen: El fideicomiso de garantía de las acciones de la sociedad concesionaria ha permitido los step in rights de los acreedores en los proyectos de concesión en Costa Rica.

Palabras clave: Fideicomiso de acciones - project finance - step in rights - concesión de obra pública con servicios públicos

Abstract: The guaranty trust of the concessionaire company's shares has allowed the borrowers to hold step in rights in concession projects in Costa Rica.

Key words: Guaranty trust - project finance - step in rights - concession of public works and public services

\footnotetext{
CONTENIDO: INTRODUCCIÓN.- I. LA CONCESIÓN DE OBRA CON SERVICIO PÚBLICO EN COSTA RICA.- II. LA SOCIEDAD ANÓNIMA NACIONAL O CONCESIONARIA.- III. LA SOCIEDAD ANÓNIMA NACIONAL O CONCESIONARIA Y SU CONCILIACIÓN CON EL CARÁCTER INTUITAE PERSONAE O PERSONALÍSIMO DEL CONTRATO DE CONCESIÓN.IV. FIDEICOMISO DE GARANTÍA DE ACCIONES DE LA SOCIEDAD ANÓNIMA NACIONAL O CONCESIONARIA.- V. CONCLUSIÓN.
}

\footnotetext{
* Es socio del bufete BLP Abogados y especialista en Derecho público, regulación económica y servicios públicos. Se desempeña como profesor de la Maestría en Derecho Público del Instituto de Enseñanza de Postgrado e Investigación de la Universidad Autónoma de Centroamérica y de la Facultad de Derecho de la Universidad Latina. Asimismo, es representante del país en la Asociación Iberoamericana de Estudios de Regulación (asier) y presidente de la Asociación Costarricense de Estudios de Regulación Económica (acere). E-mail: lortiz@blpabogados.com.
} 


\section{INTRODUCCIÓN}

Hasta hace muy poco tiempo se hacía imposible la existencia de verdaderos step in rights ${ }^{1}$ por parte de los acreedores en los proyectos de concesión de obra pública con servicios públicos en Costa Rica. De tal forma, el financiamiento de estos contratos en nuestro país comprendía un gran riesgo para los acreedores, toda vez que la única garantía con la que contaban eran los flujos mismos del proyecto, sin que fuera posible constituir garantías que les sirvieran para tomar el control del proyecto en caso de incumplimiento por parte de los sponsors o de la sociedad concesionaria.

No obstante, como paliativo a ese defecto congénito de nuestro ordenamiento jurídico, en el caso del Contrato de Concesión del Corredor San José-Caldera se logró constituir un fideicomiso de garantía con el cien por ciento de las acciones de la sociedad concesionaria.

En las siguientes líneas analizaremos, pues, su fundamento legal.

\section{LA CONCESIÓN DE OBRA CON SERVICIO PÚBLICO EN COSTA RICA}

\section{I.1. Antecedentes históricos}

El 5 de abril de 1884, Costa Rica iniciaría su primera experiencia con lo que podríamos llamar una primitiva concesión. Fue ese día que se firmó el popularmente conocido contrato-ley ${ }^{2}$ Soto-Keith, en alusión a sus suscribientes: nuestro entonces secretario de Estado en los despachos de Fomento, Hacienda y Comercio, Bernardo Soto, y Minor Cooper Keith y Meiggs, representante de la Compañía del Ferrocarril de Costa Rica. De acuerdo con los términos y condiciones de dicho contrato, la empresa privada construiría un ferrocarril que, partiendo de las inmediaciones del río Reventazón —en la línea férrea del Atlántico-, pasaría por el valle de dicho río y terminaría en la ciudad de Cartago. Adicionalmente, en virtud del contrato suscrito, el gobierno de Costa Rica cedía en plena propiedad a la Compañía del Ferrocarril de Costa Rica, por el plazo de 99 años, los ferrocarriles construidos entre Limón

1 Los acuerdos directos (step in rights) son acuerdos en los que las entidades financieras se reservan el derecho a subrogarse en la posición de la sociedad vehículo o a designar un tercero que la sustituya en caso de incumplimientos. Esto con el fin de garantizar el buen fin del proyecto hasta su entrega total y sin que sea necesario esperar a su finalización. De esta manera, se pretende conservar los contratos fundamentales del proyecto en caso de incumplimiento o quiebra, así, el contrato de construcción, de suministro, de compraventa, y el de explotación y mantenimiento. Véase Vañó Vañó, M.J. El contrato de project finance. Valencia: Tirant Lo Blanch, 2002, pp. 204-205.

2 Anteriormente vigente en nuestro país, el contrato-ley se definía como "el acto creador de relaciones jurídicas patrimoniales, suscrito entre el gobierno y un sujeto particular, que es aprobado o ratificado por la Asamblea Legislativa, y que no puede ser modificado en virtud de ley posterior, sino únicamente por acuerdo de partes" (Woodbridge, P. El contrato ley. San José: Editorial Costa Rica, 1972, p. 114). 
y Cartago, Cartago y Alajuela y el que se construiría entre Cartago y el puente del río Reventazón 3 .

Pese a esa primitiva experiencia, el concepto de concesión no aparecería si quiera mencionado en nuestro ordenamiento jurídico sino hasta la Constitución Política de 1949, la cual, en su artículo 121, inciso 14, establece que las fuerzas que puedan obtenerse de las aguas del dominio público en el territorio nacional, así como los yacimientos de carbón, las fuentes y depósitos de petróleo y cualesquiera otras sustancias hidrocarburadas - sin olvidarnos de los depósitos de minerales radioactivos existentes en el territorio nacional y los servicios inalámbricos- solo podrán ser explotados por la administración pública o por particulares, de acuerdo con la ley o mediante concesión especial otorgada por tiempo limitado y con arreglo a las condiciones y estipulaciones que establezca la Asamblea Legislativa.

Empero, no fue sino por medio del Reglamento de la Contratación Administrativa de 1977 que por primera vez la concesión de obra pública aparece reconocida expresamente por nuestro derecho positivo. Decía el artículo 195 de ese reglamento:

Artículo 195.- La concesión de obra pública, sea aquélla respecto a la cual el concesionario se compromete a construir una obra, a darle mantenimiento y a explotarla, cobrando normalmente a los usuarios un estipendio por un tiempo determinado, en vez de demandar un precio alzado directamente de la Administración, requiere de ley especial que la autorice. En el evento de que la ley respecto a trámites, que autoriza tal procedimiento resulte omisa y en cuanto pertinentes, se aplicarán supletoriamente las disposiciones del presente Reglamento, relativas a la licitación pública y a contratos de obra.

Con todo, la ley especial que autorizaría la implementación de la concesión de obra pública tardaría diecisiete años en llegar. Así pues, en el año 1994 se aprobaría finalmente la Ley General de Concesión de Obra Pública (ley 7404), aunque su utilidad sería prácticamente nula, pues bajo su vigencia únicamente se adjudicó el contrato de concesión para el mejoramiento, la rehabilitación y el mantenimiento de la autopista Bernardo Soto, el mismo que fue adjudicado a la empresa mexicana Mariscal Hermanos (marhnos) y luego fue resuelto por la administración concedente debido al incumplimiento del concesionario cuando ni siquiera se habían iniciado las obras ${ }^{4}$.

3 Procuraduría General de la República. Contratos Northern Railway Co: resumen de conceptos. San José: Autor, 1983, pp. 26- 28 y 33.

4 Santos Castro, A.M. "La garantía de acuerdos directos bajo el modelo de financiamiento de proyectos y la cesión en contratos de concesión de obras públicas". Tesis para optar por el grado de licenciada en Derecho (no publicada). Universidad de Costa Rica, 2004.

EL FIDEICOMISO

DE ACCIONES DE

LA SOCIEDAD

CONCESIONARIA

COMO GARANTÍA

DELOS

ACREEDORES EN

LA CONCESIÓN

DE OBRA CON

SERVICIO PÚBLICO

EN COSTA RICA

THETRUST

SHARES OFTHE

CONCESSIONAIRE

COMPANY AS

SECURITY FOR

CREDITORS IN

CONCESSION OF

PUBLIC WORKS

AND PUBLIC

SERVICES IN

COSTA RICA 
Tan amarga experiencia daría pie para que, en el año 1998, la Asamblea Legislativa aprobara una nueva Ley General de Concesión de Obras Públicas con Servicios Públicos (ley 7762). Bajo el amparo de esta Ley se han adjudicado cuatro proyectos: (i) concesión del Centro Penitenciario Pococí, (ii) concesión de obra con servicio público del Corredor San José-San Ramón, (iii) concesión de obra con servicio público de la Carretera San José-Caldera y (iv) concesión de obra pública con servicio público de la Terminal Granelera de Puerto Caldera. De estos cuatro proyectos, el primero fue rescindido por la administración concedente sin siquiera haber iniciado, mientras que el segundo se encuentra en fase de cierre financiero. Por su lado, los dos últimos ya han dado inicio y se encuentran en ejecución.

\subsection{Naturaleza jurídica}

Nuestra Ley General Concesión de Obras Públicas con Servicios Públicos regula, en su artículo primero, inciso 1, dos tipos de contratos de concesión: (a) el contrato de concesión de obra pública y (b) el contrato de obra con servicio público. En el inciso 2 de ese mismo artículo se define la concesión de obra con servicio público de la siguiente forma:

b) Concesión de obra con servicio público: contrato administrativo por el cual la Administración encarga a un tercero, el cual puede ser persona pública, privada o mixta, el diseño, la planificación, el financiamiento, la construcción, conservación, ampliación o reparación de cualquier bien inmueble público, así como su explotación, prestando los servicios previstos en el contrato a cambio de contraprestaciones cobradas a los usuarios de la obra o a los beneficiarios del servicio o de contrapartidas de cualquier tipo pagadas por la Administración concedente.

De la anterior definición se aprecia claramente que la concesión de obra con servicio público está conformada por dos etapas: una primera que comprende la construcción completa de la obra pública que haya determinado la administración concedente y una segunda de explotación de la obra y prestación de los servicios públicos previstos en el contrato en la que el concesionario recibe las contraprestaciones pactadas, principalmente mediante el cobro de tarifas a los usuarios de la obra y del servicio público.

El contrato bajo estudio se trata, entonces, de la combinación de ambas etapas bajo el alero de un único contrato nominado con la pretensión de — parafraseando a Dromi — sumar la ejecución de la obra pública y la prestación del servicio público consecuente en aquellos casos en que la obra y el servicio guardan conexión, concurrencia o continuidad, en 
aras de instaurar una economía de escala, minimizar la complejidad técnica y facilitar la asistencia financiera ${ }^{5}$.

A partir de la anterior explicación se hace necesario definir y delimitar el alcance de ambos contratos — concesión de obra y concesión de servicio público_- a fin de poder comprender la naturaleza jurídica que ambos llegan a tener combinados bajo la figura de la concesión de obra con servicio público.

En relación con la concesión de obra pública, la doctrina nacional la ha definido como aquel contrato administrativo por medio del cual la administración pública delega en un particular la ejecución de una obra pública, la cual será construida por el concesionario a su costo y riesgo; a cambio, la administración le otorga el privilegio de explotarla durante el lapso necesario para amortizar el capital y obtener intereses, aunque la administración mantiene la titularidad del bien concesionado ${ }^{6}$.

Por su parte, el contrato de concesión de servicios públicos consiste en un contrato administrativo donde la administración delega temporalmente en un particular el ejercicio de la prestación de un servicio público determinado, a riesgo y cuenta suya, a cambio de una contraprestación económica pagada por los usuarios, aunque no se excluye la posibilidad de que la propia administración concedente cancele una parte o la totalidad de las contraprestaciones económicas?

Ahora bien, una vez establecidos sus contornos jurídicos, es preciso adentrarse en la filosofía que subyace e impulsó la Ley General de Concesión de Obra Pública con Servicios Públicos a fin de comprender integralmente su naturaleza. En este sentido, nótese que el propósito del legislador al aprobar esta ley fue el de contar con un instrumento jurídico que permitiera la atracción de la inversión privada en la construcción, conservación, ampliación o reparación de cualquier bien o inmueble público. No obstante ello, si bien el contrato de concesión de obra pública con servicios públicos se asemeja a los Build, Transfer and Operate (BTO) de la práctica internacional de project finance, lo cierto es que la ley no lo instituyó como un típico negocio financiero, sino que, por el contrario, procuró mantenerlo apegado al principio intuitae personae que tradicionalmente lo ha caracterizado.

De esta forma, el contrato de concesión de obra con servicio público se caracteriza por ser personalísimo, lo que implica que las condiciones del oferente son determinantes para su selección. En razón de ello, el concesionario es seleccionado por la administración pública en virtud

5 Dromi, R. Licitación pública. Buenos Aires: Ediciones Ciudad Argentina, 1996.

6 González González, T. "Análisis de la Sociedad Anónima Nacional o Concesionaria y su problemática en el ordenamiento jurídico costarricense: el caso de la carretera San José-Caldera". Tesis para optar por el grado de licenciada en Derecho (no publicada). Universidad de Costa Rica, 2007.

7 lbíd.

\section{EL FIDEICOMISO \\ DE ACCIONES DE \\ LA SOCIEDAD \\ CONCESIONARIA \\ COMO GARANTÍA \\ DELOS}

ACREEDORES EN

LA CONCESIÓN

DE OBRA CON

SERVICIO PÚBLICO

EN COSTA RICA

THETRUST

SHARES OF THE

CONCESSIONAIRE

COMPANY AS

SECURITY FOR

CREDITORS IN

CONCESSION OF

PUBLIC WORKS

AND PUBLIC

SERVICES IN

COSTA RICA 
de sus características únicas y específicas que lo califican para el desarrollo adecuado del objeto contractual. Como ha señalado la Procuraduría General de la República, "la calificación de la Administración supone, entonces, que el concesionario cumple con los requerimientos técnicos necesarios y presenta la mejor oferta económica para dar cabal cumplimiento al contrato"s.

Ese carácter personalísimo del contrato de concesión deriva del necesario procedimiento de licitación pública, que constituye el medio a través del cual la administración pública se asegura que la elección recaiga en aquel oferente que haya demostrado y acreditado ser el más idóneo para ejecutar el objeto contractual. Al ser el contrato de concesión intuitae personae o personalísimo por excelencia, una vez adjudicada la licitación pública correspondiente le compete al adjudicatario desarrollar las actividades necesarias para cumplir con el objeto contractual. De ahí que, si el concesionario es seleccionado por la administración pública respectiva con ocasión de la calificación técnica que acredita en su oferta para la ejecución de la obra y la explotación de los servicios, debe proceder a ejecutar el objeto del contrato por sí mismo — salvo las subcontrataciones que autoriza el ordenamiento jurídico-, toda vez que su selección se verificó sobre la base que determinó la voluntad de la administración licitante.

En este sentido, la Sala Constitucional de la Corte Suprema de Justicia ha señalado sobre que:

Así, una característica típica de la contratación administrativa es que crea una obligación o un derecho personal a cargo o en favor del contratante, según se esté en presencia de "colaboración" o "atribución", respectivamente; dicho en otros términos, se trata de un acto intuitae personae. Así resulta preponderante la elección de la autoridad concedente respecto del concesionario cuya competencia técnica y capacidad financiera y ética garanticen la mejor ejecución del servicio público. De ese carácter personalísimo de la contratación administrativa se desprende el corolario de que el cumplimiento de las obligaciones contenidas en el contrato le corresponden personalmente al concesionario lo que no excluye la posibilidad de una transferencia de la concesión bajo ciertos supuestos. La confianza que le ha sido acordada por la Administración no puede ser alterada por una transmisión a tercero no autorizada administrativamente, motivo por el cual el concesionario está obligado a ejecutar por sí mismo la concesión; el principio intuitae personae entraña la ilicitud de la cesiones y subcontrataciones no autorizadas ${ }^{9}$ (énfasis añadido). 
La sociedad anónima nacional o concesionaria está estructurada a horcajadas entre el Derecho público y el Derecho privado. En efecto, los calificativos "nacional" y "concesionaria" modifican algunas de las características intrínsecas de las sociedades anónimas ordinarias, aquellas reguladas por nuestro Código de Comercio en los artículos 102 y siguientes. De conformidad con lo que establecen los numerales 31, inciso 1, de la Ley General de Concesión de Obra Pública con Servicios Públicos y 45.1 de su reglamento, en nuestro ordenamiento jurídico no es el propio adjudicatario de la respectiva licitación pública el que recibe la calificación de concesionario - sea este una compañía, un consorcio o una persona física一, sino, más bien, la llamada sociedad anónima nacional que ese adjudicatario debe constituir a fin de suscribir el contrato de concesión con la administración concedente. De esta forma, es la sociedad anónima nacional la que resulta obligada a ejecutar las obras y prestar los servicios acordados en el contrato de concesión, sin perjuicio de la solidaridad del adjudicatario que la propia ley establece.

Ahora bien, el concesionario constituye un típico ejemplo del ejercicio privado de funciones públicas. En razón de ello, la relación jurídica conformada entre el Estado y el concesionario denota una gran proximidad e intensidad. Así se crea entre ambos un ámbito jurídico de naturaleza especial, en el cual existe un control más intenso por parte del Estado que el existente en otras modalidades de contratos administrativos, habida cuenta de que, como lo ha establecido la Sala Constitucional, "en la concesión de servicio público, por vía de principio, la interpretación de las normas que lo regulan, debe ser en protección de los intereses públicos, por lo que debe velar la Administración y no a favor del concesionario" ${ }^{\prime \prime}$.

De acuerdo con lo anterior, los derechos y garantías del concesionario deben interpretarse y aplicarse conforme al fin de la relación especial de sujeción establecida ${ }^{11}$ y a la mejor satisfacción del interés público, lo que viene a autorizar una minimización del principio de legalidad en la actuación de la administración concedente.

10 Sala Constitucional de la Corte Suprema de Justicia, resolución 2101-91 de las 08:45 horas del 18 de octubre de 1991.

11 A diferencia de otros ordenamientos jurídicos donde la figura de la especial sujeción o supremacía especial ha sido incorporada a base de jurisprudencia, en Costa Rica la figura es parte del Derecho positivo por disposición del artículo 14 de la Ley General de la Administración Pública (ley 6227) que, a la letra, dice: "Artículo 14.- 1. Los principios generales de derecho podrán autorizar implícitamente los actos de la Administración Pública necesarios para el mejor desarrollo de las relaciones especiales creadas entre ella y los particulares por virtud de actos o contratos administrativos de duración. 2. Las limitaciones y las sanciones disciplinarias, en este caso, podrán alcanzar hasta la suspensión temporal de los derechos y bienes creados por la Administración dentro de la relación especial, pero no la negación ni la supresión de los mismo, ni de los otros propios del particular. 3. El Juez tendrá contralor de legalidad sobre los actos de la Administración dentro de este tipo de relaciones".

EL FIDEICOMISO

DE ACCIONES DE

LA SOCIEDAD

CONCESIONARIA

COMO GARANTÍA

DELOS

ACREEDORES EN

LA CONCESIÓN

DE OBRA CON

SERVICIO PÚBLICO

EN COSTA RICA

THETRUST

SHARES OF THE

CONCESSIONAIRE

COMPANY AS

SECURITY FOR

CREDITORS IN

CONCESSION OF

PUBLIC WORKS

AND PUBLIC

SERVICES IN

COSTA RICA 
En este contexto, la sociedad anónima nacional o concesionaria está vinculada a determinadas finalidades de interés general que le confieren una virtualidad expansiva a la regulación administrativa que impera sobre esta. Por lo tanto, el concesionario — sin dejar de ser una persona jurídica privada - debe cumplir las obligaciones acordadas con la administración concedente con sometimiento pleno y estricto no solo a las bases y términos de la contratación, sino también a numerosos controles administrativos, tales como órdenes y directrices.

Aquellas normas ordenan la constitución de una sociedad anónima nacional a fin de instrumentalizar el contrato de concesión, pues delimitan su objeto social única y exclusivamente a la ejecución del contrato, establecen una causa de disolución especial de la sociedad —una vez terminada la concesión y comprobada la inexistencia de pasivos contingentes a cargo de ella-, fijan específicamente los parámetros para determinar su capital social, e imponen los porcentajes de participación que deben tener los socios en el capital social. Todos ellos consisten en condicionantes externos inimaginables en cualquier otro tipo de sociedad anónima ordinaria.

En consecuencia, la sociedad anónima nacional está sujeta a detalladas regulaciones - tanto en su marco externo, como también en su propia vida interna-, cuyos aspectos técnicos, financieros, comerciales o contables, así como el quantum y el modo de su actividad, están también sometidos a normas y directrices especiales que la administración concedente dicta para ella.

Así, pues, la sociedad anónima nacional o concesionaria constituye una sociedad anónima "publificada", en la que la ley especial determina - y, en otros casos, delega - en la administración concedente la regulación obligatoria de sus elementos constitutivos y operativos, de lo que son claros ejemplos los artículos 15.a, 16.a, 17.d, 18.a, 18.d y 19.b de la Ley General de Concesión de Obras Públicas con Servicios Públicos.

Por lo tanto, queda latente la pregunta de cómo conciliar la figura de la sociedad anónima nacional o concesionaria antes explicitada con el carácter personalísimo del contrato de concesión.

\section{II. LASOCIEDADANÓNIMANACIONALOCONCESIONARIA Y SU CONCILIACIÓN CON EL CARÁCTER INTUITAE PERSONAE O PERSONALÍSIMO DEL CONTRATO DE CONCESIÓN}

De conformidad con el artículo 182 de la Constitución Política, la licitación pública constituye un procedimiento esencial y necesario en la contratación administrativa. A diferencia de lo que acontece en el ámbito privado, en el que puede contratarse a quien se desea, cuando se trata 
de la administración pública su elección se somete a determinadas reglas de obligado cumplimiento, dirigidas a que la elección del contratista se realice siguiendo criterios objetivos.

Ahora bien, como se explicó anteriormente, en nuestro ordenamiento jurídico quien recibe la calificación de concesionario no es el adjudicatario, sino la persona jurídica conformada con la participación de este en su capital social: la llamada sociedad anónima nacional o concesionaria. En razón de ello, dicha sociedad anónima nacional o concesionaria asume los derechos y las obligaciones nacidas del acto de adjudicación y del posterior perfeccionamiento de la relación contractual en favor del adjudicatario, toda vez que el acto de adjudicación se dicta en su favor, y es respecto de ese - y no de la sociedad concesionaria- que la administración concedente determina la aptitud para ejecutar el contrato de concesión específico. Ello significa que la sociedad anónima concesionaria o nacional se hace cargo o acepta los derechos y las obligaciones preexistentes del adjudicatario, aquellos obtenidos de conformidad con las bases del procedimiento de licitación pública tramitado.

En consecuencia, para resguardar el carácter personalísimo (intuitae personae) del contrato de concesión, no solo se ha establecido la obligación de que el adjudicatario domine la sociedad concesionaria y mantenga la titularidad de la mayoría del capital social durante toda la vigencia del contrato (51\%), sino que, además, por interpretación de la Contraloría General de la República, de ser el adjudicatario un consorcio, el contenido del acuerdo consorcial mediante el cual las partes estipulan sus derechos y obligaciones respecto de la concesión debe o pasar a formar parte íntegra del contrato social de la sociedad anónima nacional creada, o bien mantener su vigencia por todo el tiempo de ejecución contractual ${ }^{12}$. Ello es así, habida cuenta de que, si la ley recurre a la constitución de la sociedad concesionaria, es única y exclusivamente con el objeto de facilitar un financiamiento por el mercado, mas no para desnaturalizar, trastocar, transformar o cambiar al verdadero concesionario.

\section{IV.FIDEICOMISO DE GARANTÍA DE ACCIONES DE LA SOCIEDAD ANÓNIMA NACIONAL O CONCESIONARIA}

Como hemos ya adelantado en los acápites precedentes, el contrato de concesión de obra con servicio público en Costa Rica tiene al menos dos particularidades que lo disocian de la práctica internacional de project finance, a saber:

EL FIDEICOMISO DE ACCIONES DE LA SOCIEDAD CONCESIONARIA COMO GARANTÍA DELOS

ACREEDORES EN LACONCESIÓN

DE OBRA CON SERVICIO PÚBLICO en COSTA RICA

THETRUST

SHARES OFTHE

CONCESSIONAIRE

COMPANY AS

SECURITY FOR

CREDITORS IN

CONCESSION OF

PUBLIC WORKS

AND PUBLIC

SERVICES IN

COSTA RICA 
- Se consideran propiedad de la administración concedente las obras que se construyan, así como las que se incorporen al inmueble, conforme sea el avance de la construcción.

- Por disposición del artículo 31.1 de la lgcopsp y el 45 de su reglamento, el adjudicatario debe crear una sociedad anónima nacional o concesionaria, que es aquella con la cual se firma el contrato de concesión y la que viene obligada a ejecutarlo. Sin embargo, para resguardar el carácter personalísimo (intuitae personae) del contrato de concesión, el numeral 31 de la lgcopsp no solo ha establecido la obligación de que el adjudicatario domine la sociedad concesionaria manteniendo la titularidad de la mayoría del capital social (51\%), sino, además, de que aquel (el adjudicatario) sea solidariamente responsable con esta sociedad anónima. De ahí que, contrario a la práctica internacional de project finance, se exige recurso contra él o los sponsors del proyecto en nuestro ordenamiento jurídico. Así, tanto el adjudicatario como la sociedad anónima nacional o concesionaria se reputan deudores únicos de todas las obligaciones contractuales adquiridas en la licitación pública, por lo que es posible para la administración concedente dirigirse contra el adjudicatario y/o contra la sociedad anónima nacional o concesionaria indistintamente, o bien contra ambos a la misma vez.

Lo anterior hace que, en principio, la única garantía con la que cuentan los acreedores sean los flujos mismos del proyecto, sin que la ley haya previsto verdaderos step in rights que garanticen a aquellas ante un incumplimiento por parte del concesionario. Por ello, ante tal laguna del ordenamiento jurídico, resultaba esencial implementar la figura del fideicomiso de garantía con el 100\% de las acciones de la sociedad anónima nacional o concesionaria, a fin de resguardar adecuadamente los derechos e intereses de los acreedores y hacer atractivos los proyectos de concesión en nuestro país.

De esta forma, se ideó e implementó un mecanismo legal por medio del cual se transfieren las acciones de los sponsors (fideicomitentes) a un fiduciario, quien administra y custodia las acciones de la sociedad concesionaria solamente en garantía y según las instrucciones del contrato de fideicomiso en favor de los acreedores del proyecto (fideicomisarios o beneficiarios). Así, en el caso de que se verifique un incumplimiento en la operación de crédito, el fiduciario debe sacar a remate las acciones mediante una policitación pública, y su adjudicación queda sujeta — como condición de validez y eficaciaa que el rematario cumpla al menos con las mismas condiciones requeridas por el cartel de licitación, así como también a que tanto 
la administración concedente como la Contraloría General de la República ${ }^{13}$ autoricen la cesión de las acciones. Por el contrario, si el fideicomitente cumple con sus obligaciones y repaga el préstamo, el fiduciario entrega de vuelta las acciones al fideicomitente y las libera de la propiedad fiduciaria en que se encontraban.

A su vez, ello implica la transferencia de las acciones de un fideicomitente a un fiduciario, quien lo administra o custodia solamente en garantía y según las instrucciones del contrato de fideicomiso en favor

13 Sobre la naturaleza jurídica y las funciones de la Contraloría General de la República, los artículos 183 y 184 de la Constitución Política de la República de Costa Rica señalan: "Artículo 183.- La Contraloría General de la República es una institución auxiliar de la Asamblea Legislativa en la vigilancia de la Hacienda Pública; pero tiene absoluta independencia funcional y administrativa en el desempeño de sus labores. La Contraloría está a cargo de un Contralor y un Subcontralor. Ambos funcionarios serán nombrados por la Asamblea Legislativa, dos años después de haberse iniciado el período presidencial, para un término de ocho años; pueden ser reelectos indefinidamente, y gozarán de las inmunidades y prerrogativas de los miembros de los Supremos Poderes. El Contralor y Subcontralor responden ante la Asamblea por el cumplimiento de sus funciones, y pueden ser removidos por ella, mediante votación no menor de las dos terceras partes del total de sus miembros, si en el expediente creado al efecto se les comprobare ineptitud o procederes incorrectos. Artículo 184.- Son deberes y atribuciones de la Contraloría: 1) Fiscalizar la ejecución y liquidación de los presupuestos ordinarios y extraordinarios de la República. No se emitirá ninguna orden de pago contra los fondos del Estado sino cuando el gasto respectivo haya sido visado por la Contraloría; ni constituirá obligación para el Estado la que no haya sido refrendada por ella; 2) Examinar, aprobar o improbar los presupuestos de las Municipalidades e instituciones autónomas, y fiscalizar su ejecución y liquidación; 3) Enviar anualmente a la Asamblea Legislativa, en su primera sesión ordinaria, una memoria del movimiento correspondiente al año económico anterior, con detalle de las labores del Contralor y exposición de las opiniones y sugestiones que éste considere necesarias para el mejor manejo de los fondos públicos; 4) Examinar, glosar y fenecer las cuentas de las instituciones del Estado y de los funcionarios públicos; 5) Las demás que esta Constitución o las leyes le asignen". Sobre el traspaso del $51 \%$ de acciones de la sociedad anónima nacional o concesionaria, el reglamento de la Ley General de Concesión de Obras Públicas con Servicios Públicos dice: "Artículo 45.- Suscripción del contrato y constitución de la sociedad anónima [...] 45.1 El contrato de concesión se suscribirá con la sociedad anónima constituida para tal efecto, una vez firme el acto de la adjudicación. Esta sociedad tendrá como objeto único y exclusivo la ejecución del contrato de concesión y le serán aplicables las normas del Código de Comercio. 45.2 Para constituir la sociedad anónima, el adjudicatario dispondrá de un plazo máximo de noventa días naturales, contados a partir de la firmeza del acto de adjudicación. El capital social inicial será determinado en el cartel de la licitación sobre un porcentaje del gasto total proyectado para la construcción de la obra y, una vez concluida, para su explotación. Cada año, al iniciarse el nuevo período fiscal, la Administración concedente definirá las variaciones del gasto total proyectado, con el propósito de que se efectúen los ajustes correspondientes en el capital social. El concesionario dispondrá de treinta días hábiles para ajustar el capital y su incumplimiento se considerará falta grave. 45.3 Cuando razones o circunstancias de interés público muy calificadas, de fuerza mayor o de caso fortuito así lo justifiquen y en el tanto con ello no se violenten los principios constitucionales de la contratación administrativa, la Administración Concedente, mediante un acto debidamente razonado, podrá autorizar la cesión de los derechos y obligaciones del concesionario, comprendiendo dentro de estos el traspaso del cincuenta y uno por ciento $(51 \%)$ del capital social de la sociedad concesionaria. En estos casos se requerirá adicionalmente autorización previa de la Contraloría General de la República. 45.4 Para autorizar la cesión de derechos y obligaciones del concesionario o el traspaso de las acciones de la sociedad concesionaria, la Administración deberá verificar que las características y condiciones del virtual cesionario mejoren y no lesionen la consecución del interés público pretendido por la concesión, según la etapa presente o futura en que la concesión se encuentre o se vaya a encontrar. 45.5 En ningún caso el adjudicatario o la Administración podrán ceder o aceptar, según corresponda, la cesión de los derechos y obligaciones de la sociedad concesionaria ni el traspaso del capital social de ésta, en contra de las prohibiciones establecidas por el artículo 22 de la Ley de Contratación Administrativa. 45.6 No se considerará como cesión la disposición que haga el Concesionario sobre la forma y destino de los pagos que reciba como producto de la explotación de la Concesión. 45.7 Sin perjuicio de las normas generales de contabilidad aplicable a las sociedades anónimas, la Administración concedente queda facultada para exigir, a través del cartel, los registros de información contable que se consideren necesarios para fiscalizar el contrato de concesión y a la sociedad anónima concesionaria. $45.8 \mathrm{El}$ contrato de concesión que se suscriba deberá ser refrendado por la Contraloría General de la República, para lo cual dispondrá de un plazo máximo de hasta treinta días hábiles, contados a partir de su recepción".

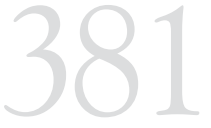

EL FIDEICOMISO

DE ACCIONES DE

LA SOCIEDAD

CONCESIONARIA

COMO GARANTÍA

DELOS

ACREEDORES EN

LACONCESIÓN

DE OBRA CON

SERVICIO PÚBLICO

EN COSTA RICA

THETRUST

SHARES OFTHE

CONCESSIONAIRE

COMPANY AS

SECURITY FOR

CREDITORS IN

CONCESSION OF

PUBLIC WORKS

AND PUBLIC

SERVICES IN

COSTA RICA 
de un fideicomisario o beneficiario. En efecto, en su resolución 200109392 de 14:54 del 19 de septiembre de 2001, la Sala Constitucional señaló: "III. Sobre el fideicomiso en garantía. La doctrina más calificada sobre los contratos mercantiles define al contrato de fideicomiso como el negocio jurídico, en virtud del cual una persona llamada fiduciante o fideicomitente transfiere uno o más bienes especificados a otra, llamada fiduciario, que se obliga a administrarlos o enajenarlos para cumplir una finalidad determinada por el fideicomitente $[\ldots]$ ".

Y agrega la sala en dicha resolución: "De esta manera, en términos muy generales, mediante el contrato de fideicomiso el fideicomitente le transfiere la propiedad de ciertos bienes al fiduciario con el propósito de que los administre de acuerdo con los fines del fideicomiso [...]".

Esto es lo que comúnmente se conoce como "propiedad fiduciaria", más detalladamente previsto en el artículo 648 del Código de Comercio (libro segundo, título I, capítulo XII), que estipula que "puede constituirse un fideicomiso sobre bienes o derechos en garantía de una obligación del fideicomitente con el fideicomisario. En tal caso, el fiduciario puede proceder a la venta o remate de los bienes en caso de incumplimiento, todo de acuerdo con lo dispuesto en el contrato".

Lo anterior ratifica las condiciones especiales de la propiedad fiduciaria, en la que - por ser totalmente diferente a un traspaso en propiedad común y corriente- ni siquiera causa el pago de los derechos de registro, timbre o impuestos de traspaso, de acuerdo con el numeral 662 del Código de Comercio. Asimismo, ese mismo artículo establece que, si los bienes en propiedad fiduciaria son devueltos al fideicomitente, tampoco hay pago de derechos de registro, timbres o impuestos, lo que únicamente sucede en el caso de que el traspaso se realice en favor de un tercero.

Del mismo modo, dicho traspaso se hace como parte de un fideicomiso de garantía en donde los socios de la sociedad concesionaria traspasan sus acciones al fideicomiso, pero mantienen el derecho a que se les devuelvan en la misma proporción en la que hoy son dueños, al pagarse el crédito y finalizar el fideicomiso.

Por lo tanto, es claro que la intención en este supuesto no es sustituir o mutar al adjudicatario original mediante el traspaso del 100\% de las acciones al fiduciario para que este sea quien ejecute la concesión - que es la ratio legis que inspira las limitaciones de la ley y el reglamento de concesión de las obras públicas con servicios públicos-, sino únicamente constituir una garantía en favor de los acreedores del proyecto. Por lo mencionado, es solamente en el caso de un eventual incumplimiento de las obligaciones de la sociedad concesionaria con respecto a los acreedores del proyecto que las acciones fideicometidas pueden — eventualmente — pasar a manos de un tercero, con la previa 
autorización del Consejo Nacional de Concesiones y de la Contraloría General de la República, quienes, en ese momento, verifican que el rematario de las acciones y eventual nuevo adjudicatario, cumpla con las condiciones expresamente previstas en el mismo cartel de licitación. En tal virtud, lo cierto es que esos efectos jurídicos son tan solo hipotéticos y, en todo caso, diferidos en el tiempo.

\section{CONCLUSIÓN}

Cuando la realidad del país exige con premura obras de infraestructura y servicios públicos de alta calidad que el Estado, con su exiguo presupuesto, no puede proveer, surgen las concesiones como una vía de colaboración y sinergia entre el gobierno, la sociedad y el mercado. Con esta técnica, a la vez que se satisfacen las urgentes necesidades sociales, se impide que el Estado asuma una grave responsabilidad por la discordancia fatal entre lo que se le exige, lo que se compromete a hacer y lo que realmente hace ${ }^{14}$.

Por ello, al ser la administración concedente la que mejor conoce el interés público comprometido y también la forma en que este debe satisfacerse - con base en sus potestades discrecionales de fiscalización y control, provenientes de la relación de sujeción o supremacía especial creada entre ella y la sociedad concesionaria-, puede y debe autorizar la constitución del fideicomiso de garantía de sus acciones, siempre que ello sirva para garantizar un equilibrio entre la eficiencia de la administración y los derechos fundamentales del individuo, que, en este caso, viene a ser el derecho fundamental innominado o atípico de los administrados al buen funcionamiento de los servicios públicos y al mejoramiento de las condiciones de infraestructura pública ${ }^{15}$.

EL FIDEICOMISO

DE ACCIONES DE

LA SOCIEDAD

CONCESIONARIA

COMO GARANTÍA

DELOS

ACREEDORES EN

LA CONCESIÓN

DE OBRA CON

SERVICIO PÚBLICO

EN COSTA RICA

THETRUST

SHARES OF THE

CONCESSIONAIRE

COMPANY AS

SECURITY FOR

CREDITORS IN

CONCESSION OF

PUBLIC WORKS

AND PUBLIC

SERVICES IN

COSTA RICA 